\title{
Review Article \\ The Usefulness of Xuefu Zhuyu Tang for Patients with Angina Pectoris: A Meta-Analysis and Systematic Review
}

\author{
Guo-zhong Yi, ${ }^{1}$ Yu-qin Qiu, ${ }^{2}$ Ya Xiao, ${ }^{2,3}$ and Li-xia Yuan ${ }^{2}$ \\ ${ }^{1}$ The First College of Clinical Medicine, Southern Medical University, Guangzhou, Guangdong 510515, China \\ ${ }^{2}$ College of Traditional Chinese Medicine, Southern Medical University, Guangzhou, Guangdong 510515, China \\ ${ }^{3}$ Department of Traditional Chinese Medicine, Nanfang Hospital, Southern Medical University, Guangzhou, Guangdong 510515, China
}

Correspondence should be addressed to Li-xia Yuan; yiguozhong09@126.com

Received 7 April 2014; Revised 10 August 2014; Accepted 10 August 2014; Published 31 August 2014

Academic Editor: Myeong Soo Lee

Copyright (C) 2014 Guo-zhong Yi et al. This is an open access article distributed under the Creative Commons Attribution License, which permits unrestricted use, distribution, and reproduction in any medium, provided the original work is properly cited.

\begin{abstract}
Objective. To evaluate the efficacy of Xuefu Zhuyu Tang (XFZYT) for treating angina pectoris (AP). Methods. Six databases were searched (up to December, 2013). Eligible randomized controlled trials (RCTs) evaluating the efficiency of XFZYT plus traditional antianginal medications (TAMs) compared with TAMs alone in patients with AP were included. The outcomes were relief of anginal symptoms (RAS) and improvement of electrocardiogram (ECG) and blood high-density lipoprotein cholesterol (HDL-C) level. Result. Finally 14 RCTs were included. There were evidences that XFZYT combined with TAMs was more effective in improving RAS $(\mathrm{RR}=1.29 ; 95 \% \mathrm{CI}=[1.20,1.38])$, ECG $(\mathrm{RR}=1.37 ; 95 \% \mathrm{CI}=[1.22,1.54])$, and blood HDL-C level $(\mathrm{MD}=0.29 \mathrm{mmol} / \mathrm{L} ; 95 \%$ $\mathrm{CI}=[0.23,0.35])$ compared with TAMs alone. Our meta-analysis also showed the pooled number needed to treat (NNT) of the group with stable angina pectoris (SAP) was smaller in improving RAS (4.2 versus 5.7) and ECG (3.1 versus 5.5) compared with the group with both SAP and unstable angina pectoris (UAP). Conclusion. Combination therapy with XFZYT and TAMs is more effective in treating AP compared with TAMs alone. And XFZYT may be a more suitable choice for the treatment of SAP. However, the findings should be interpreted with caution due to the mediocre methodological quality of the included RCTs.
\end{abstract}

\section{Introduction}

Cardiovascular diseases are the number one cause of death globally [1]. According to the World Health Organization (WHO), an estimated 17.3 million people died from cardiovascular diseases in 2008, representing $30 \%$ of all global deaths. Of these deaths, an estimated 7.3 million deaths were due to coronary heart disease. Angina pectoris is the most prevalent manifestation of coronary artery diseases and has a major negative impact on the general health status and quality of life [2].

Angina pectoris is clinically classified into stable angina pectoris (SAP) and unstable angina pectoris (UAP). Both SAP and UAP can use traditional antianginal medications (TAMs) such as organic nitrates, antiplatelet drugs, antithrombotic drugs, and $\beta$ blockers. Antiplatelet drugs include aspirin, platelet glycoprotein IIb/IIIa inhibitor, and clopidogrel, antithrombotic drugs include heparin and low-molecularweight heparin, and $\beta$ blockers included metoprolol tartrate
$[3,4]$. Despite the effectiveness of TAMs, episodes of angina may still persist or become even worse, and many patients cannot tolerate a combination of TAMs due to their many serious adverse effects, such as antithrombotic complications, decreasing heart rate or blood pressure, and other hemodynamic changes $[5,6]$. Therefore, we need to research a new medication which is effective and tolerant in improving the symptoms of angina and will provide an alternative option for patients.

Xuefu Zhuyu Tang (XFZYT) originated from the "Corrections on the Errors of Medical Works" in Qing Dynasty. It is a very famous traditional Chinese formula in promoting Qi circulation and removing blood stasis according to traditional Chinese medicine (TCM) theory [7]. This formula consists of rehmannia root (shengdi), peach seed (taoren), safflower (honghua), Chinese angelica (danggui), red peony root (chishao), platycodon root (jiegeng), orange fruit (zhiqiao), hare's ear root (chaihu), sichuan lovage root (chuangxiong), two-toothed achyranthes root (niuxi), and prepared liquorice 
root (gancao). Some pharmacological researches showed that XFZYT could improve blood rheology, reduce blood lipid level, and prevent antimyocardial ischemia $[8,9]$. This Chinese herbal medicine (CHM) is commonly used for the treatment of patients with cardiovascular diseases $[7,10]$.

How about the efficacy of XFZYT in improving AP outcomes and the application of XFZYT in the treatment of different AP subtypes? We therefore conducted an updated systematic review and meta-analysis of published RCTs to answer these questions.

\section{Materials and Methods}

2.1. Search Strategy. Two authors (G. Z. Yi and Y. Q. Qiu) systematically searched the Medline database (1989-December 2013), Cochrane Library (1993-December 2013), Chinese National Knowledge Infrastructure database (CNKI, 1989December 2013), Chinese Biomedical Literature database (CBM, 1990-December 2013), Wanfang database (1989December 2013), and Chinese Scientific Journal database (VIP, 1989-December 2013). The following keywords were used: coronary heart disease, $\mathrm{CHD}$, angina pectoris, $\mathrm{AP}$, and Xuefu Zhuyu.

2.2. Eligibility Criteria. We included RCTs met criteria as follows: (1) involving patients who were diagnosed with SAP or UAP according to the American College of Cardiology Foundation/American Heart Association (ACCF/AHA) Guideline for the Diagnosis and Management of Patients with Unstable Ischemic Heart Disease [11], the International Society and Federation of Cardiology/World Health Organization (ISFC/WHO) guideline [12], or the Chinese Society of Cardiology (CSC) guidelines [13, 14]; (2) comparing XFZYT plus TAMs with TAMs alone for maintenance therapy for at least 4 weeks and the two groups were comparable on the basis of the characteristic of patients and studies, such as gender, age, and sample size; (3) using improvement of the relief of angina symptoms (RAS) and electrocardiogram (ECG) as the outcome measures [15] and quality of life (QL), blood lipid (HDL-C, LDL-C, TC, and TG) level, reduction of nitroglycerin use (RNU), and adverse events (AEs) were also included.

2.3. Data Extraction. Two researchers (G. Z. Yi and Y. Q. Qiu) independently extracted from each article the authors information, year of publication, types of AP, sample size, the number of participants in each group, percent of male and average age, criteria for inclusion and exclusion, method of randomization, details of blinding, interventions of each group, duration of treatment, criteria for outcome assessments, and data reported. Disagreements were resolved after discussion with a third researcher (Y. Xiao).

2.4. Statistical Analysis. Meta-analysis was carried out using Review Manager software (version 5.2), provided by the Cochrane Collaboration. Dichotomous data were presented as risk ratios (RRs) and continuous outcomes as mean difference (MD), both with 95\% confidence interval (CI).
The chi-squared test and $I$-squared statistic were performed to assess the heterogeneity, and heterogeneity was presented as significant when $I^{2}$ was over $25 \%$. In the absence of statistical heterogeneity, a fixed-effect model was used to pool the result; otherwise, a random-effect model was used [16]. In subgroup analysis, we used the number needed to treat (NNT) to evaluate the usefulness of XFZYT plus TAMs for each subgroup with different AP subtypes; the NNT was calculated as 1/(Therapeutic Gain). And we also performed a funnel plot of the improvement of RAS between XFZYT plus TAMs group and TAMs group to assess the publication bias.

\section{Results}

3.1. Description of Included Trials. A total of 1044 studies were identified by computer search and manual search of cited references. After further reading, we excluded 1030 studies according to the eligibility criteria. Finally, a total of 14 studies [17-30] were included in the meta-analysis and systematic review, of which 4 studies $[18,21,26,28]$ included patients with SAP, 2 studies $[23,24]$ included patients with UAP, and 8 studies $[17,19,20,22,25,27,29,30]$ included patients with SAP or UAP. All these studies were published in Chinese. Figure 1 is a flow diagram of studies selection process.

All 14 studies included were RCTs, and all of them recruited participants for treatment with XFZYT combined with TAMs versus TAMs. Most of the studies used the improvement of RAS and ECG as the primary outcome measures; the reduction of nitroglycerin use (RNU) and blood lipid level were also reported in some studies. One study [23] used the Seattle Angina Questionnaire (SAQ) [31] and Short Form-36 (SF-36) [32] to evaluate the quality of life of patients after treatment. The characteristics of these original studies are presented in Table 1.

3.2. Methodological Quality of Included Trials. The methodological quality of the RCTs included in our study was assessed by the criteria in the Cochrane Handbook for Systematic Review [16]. The quality of trials was evaluated as having low risk of bias, uncertain risk of bias, and high risk of bias according to the risk of trials, including sequence generation, allocation concealment, blinding, incomplete outcome data, selective outcome reporting, and other potential sources of bias. All studies had described a correct randomization method, but only $2[19,23]$ mentioned allocation concealment. 5 studies $[19,20,23,25,30]$ described blinding of participants and 4 RCTs $[19,23,25,28]$ mentioned withdrawal and dropout information. Among all these RCTs, the characteristics of participants in each study arm were similar at baseline (age, race, sex, and disease course). The details are shown in Table 2.

3.3. The Effect of XFZYT in Patients with AP. All the 14 RCTs tested XFZYT plus TAMs versus TAMs alone, and we analyzed the following outcomes: RAS (12 trials), ECG (9 trials), blood lipid (HDL-C, LDL-C, TC, and TG) level (3 trials), reduction of nitroglycerin use (2 trials), and quality of life (1 trial). 


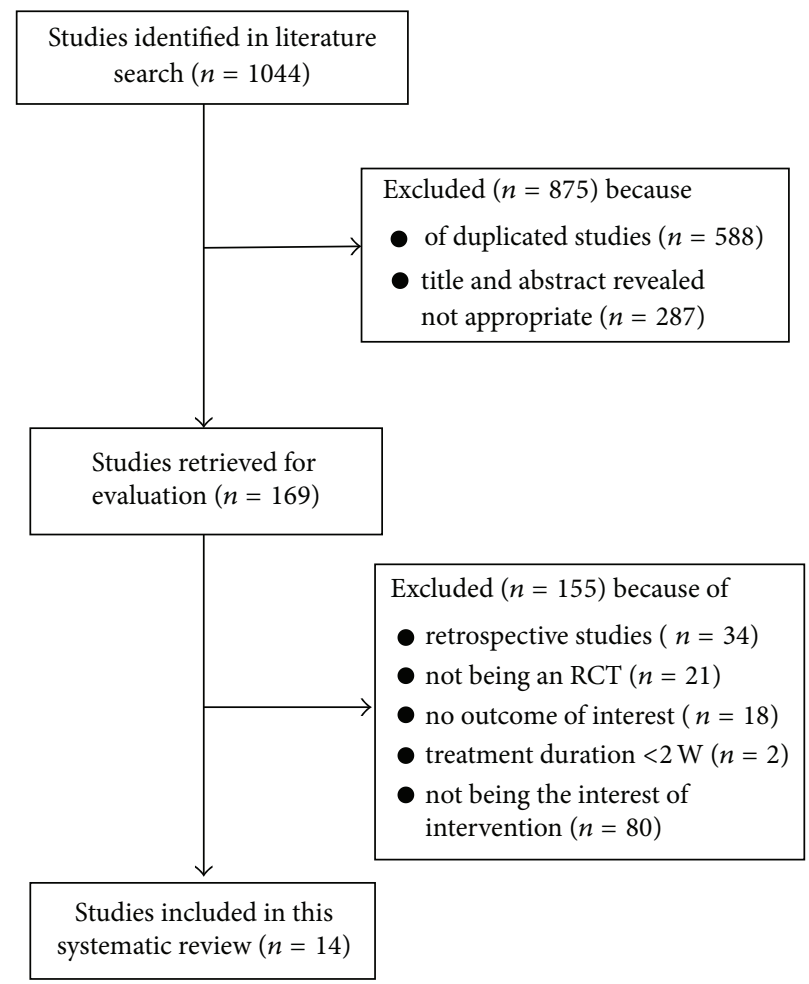

FIGURE 1: The flow diagram of study selection process.

3.3.1. RAS. The improvement of RAS was reported in 12 RCTs [17-22, 25-30] involving 992 participants and results favored XFZYT combined with TAMs group $(\mathrm{RR}=1.29 ; 95 \% \mathrm{CI}=$ $[1.20,1.38])$ without significant heterogeneity $\left(\chi^{2}=5.38\right.$; $I^{2}=0 \%$ ) (Figure 2).

3.3.2. ECG. After analyzing 9 RCTs $[17,18,20,22,24,26-$ $28,30]$ involving 683 participants, the result also indicated favoring XFZYT combined with TAMs group ( $\mathrm{RR}=1.37$; $95 \% \mathrm{CI}=[1.22,1.54])$ in the improvement of ECG and with significant homogeneity $\left(\chi^{2}=6.17 ; I^{2}=0 \%\right)$ (Figure 3$)$.

3.3.3. Blood Lipid (HDL-C, LDL-C, TC, and TG) Level. 3 RCTs $[17,18,29]$ involving 342 participants reported the improvement of blood lipid level. HDL-C was significantly increased in XFZYT combined with TAMs group $(\mathrm{MD}=$ $0.29 \mathrm{mmol} / \mathrm{L} ; 95 \% \mathrm{CI}=[0.23,0.35])$ and without significant heterogeneity $\left(\chi^{2}=1.05 ; I^{2}=0 \%\right.$ ) (Figure 4$)$, while LDL-C, TG, and TC were significantly decreased in XFZYT combined with TAMs group $(\mathrm{MD}=1.08 \mathrm{mmol} / \mathrm{L}, 0.98 \mathrm{mmol} / \mathrm{L}$, and $1.27 \mathrm{mmol} / \mathrm{L} ; 95 \% \mathrm{CI}=[0.72,1.44],[-0.05,2.02,0.63,1.91])$ but with significant heterogeneity $\left(\chi^{2}=5.31,88.48\right.$, and $11.48 ; I^{2}=62 \%, 98 \%$, and $83 \%$ ) (Figures 5, 6, and 7).

3.3.4. Reduction of Nitroglycerin Use. 2 RCTs $[19,24]$ involving 121 patients showed that the dosage of nitroglycerin can be significantly reduced after the treatment with XFZYT combined with TAMs. We did not perform a meta-analysis for the significant heterogeneity $\left(\chi^{2}=13.08 ; I^{2}=92 \%\right)$. Results of the two trials are as follows: the dosage of nitroglycerin decreased from $3.96 \pm 1.27$ to $1.15 \pm 0.58$ pills/day [19] and from $2.2 \pm 0.6$ to $2.0 \pm 0.9$ pills/day [24]

3.3.5. The Quality of Life. A randomized, double-blinded, double-dummy, and placebo controlled study [23] used Seattle Angina Questionnaire (SAQ) [31] and Short Form36 (SF-36) [32] as the criteria to evaluate the efficacy of XFZYT combined with TAMs on patients with UAP after percutaneous coronary intervention (PCI). The SAQ results showed that the XFZYT combined with TAMs group could significantly improve $(P<0.05)$ the score of angina stability (AS), angina frequency (AF), and treating satisfaction (TS). And the score of body pain (BP), general health $(\mathrm{GH})$, vitality (VT), social function (SF), and role emotional (RE) of the SF36 was also significantly $(P<0.05)$ improved in the XFZYT combined with TAMs group.

3.3.6. Subgroup Analysis. For our key analysis of the add-on effect of XFZYT for treating different AP subtypes, 13 studies provided the data necessary to perform our evaluation. Of these RCTs, 1 RCT [24] involved participants with UAP, 4 RCTs $[18,21,26,28]$ involved participants with SAP, and the other 8 RCTs $[17,19,20,22,25,27,29,30]$ involved participants with SAP or UAP. Overall, (1) for patients with SAP, 94.3\% reported RAS improvement after the treatment with XFZYT plus TAMs compared with $70.7 \%$ after the treatment with TAMs only (therapeutic gain $=23.6 \%$ with a number needed to treat $(\mathrm{NNT})=4.2$ ) (Table 3$)$, and $77.0 \%$ 


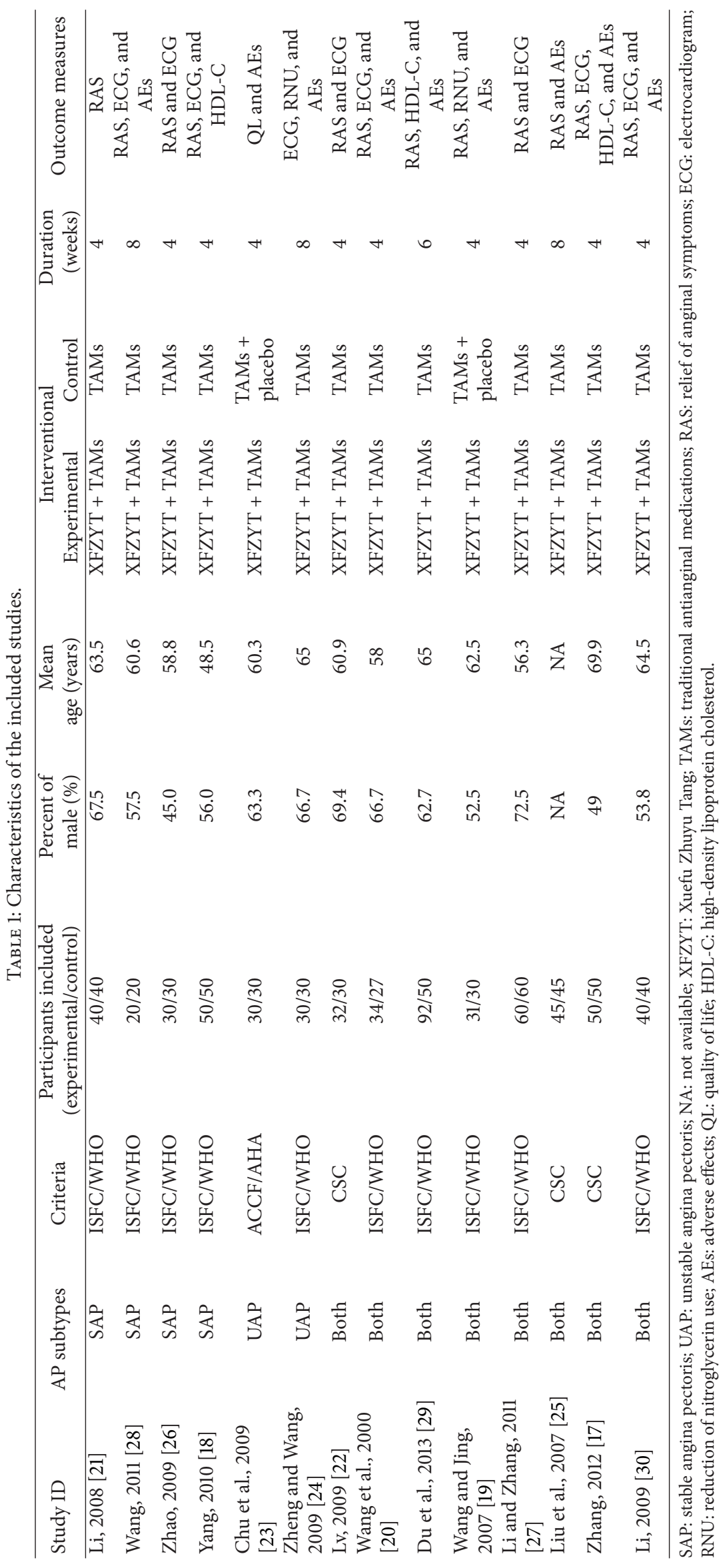




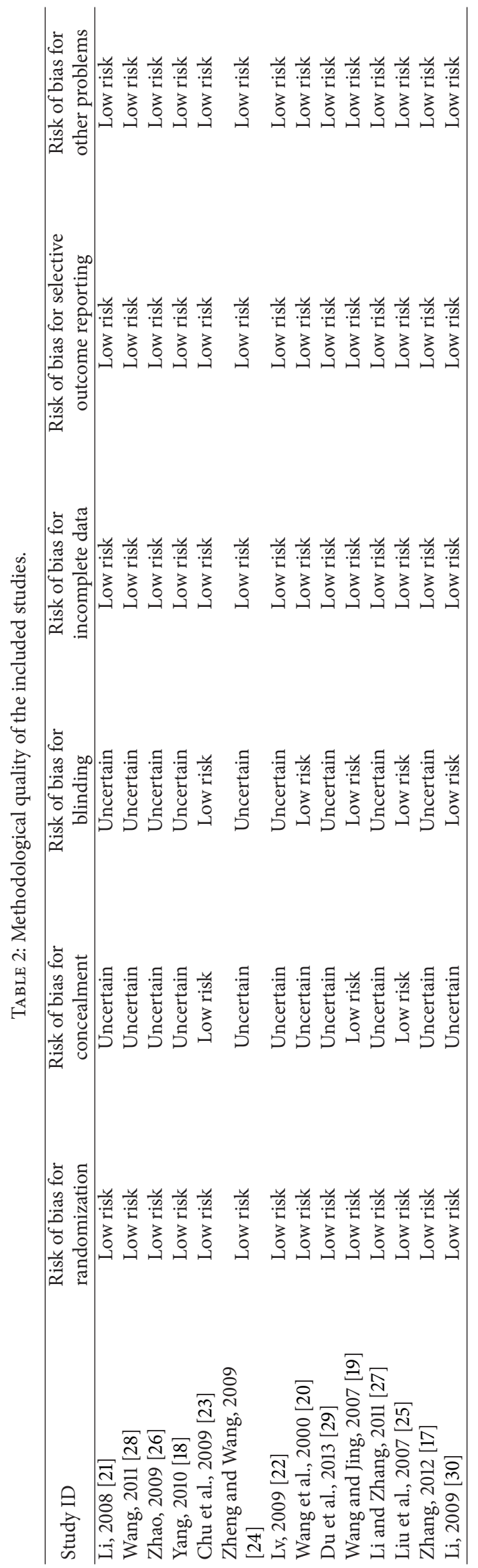




\begin{tabular}{|c|c|c|c|c|c|c|c|c|}
\hline \multirow{2}{*}{ Study or subgroup } & \multicolumn{2}{|c|}{ XFZYT and TAMs } & \multicolumn{2}{|c|}{ TAMs or plus placebo } & \multirow{2}{*}{ Weight } & Risk ratio & \multirow{2}{*}{$\begin{array}{c}\text { Risk ratio } \\
\text { M-H, fixed, 95\% CI }\end{array}$} & \\
\hline & Events & Total & Events & Total & & M-H, fixed, 95\% CI & & \\
\hline Du et al., 2013 & 73 & 92 & 32 & 50 & $12.2 \%$ & $1.24[0.98,1.56]$ & - & \\
\hline Li and Zhang, 2011 & 54 & 60 & 40 & 60 & $11.8 \%$ & $1.35[1.11,1.65]$ & - & \\
\hline Li, 2009 & 38 & 40 & 28 & 40 & $8.2 \%$ & $1.36[1.09,1.68]$ & $\mp$ & \\
\hline $\mathrm{Li}, 2008$ & 38 & 40 & 28 & 40 & $8.2 \%$ & $1.36[1.09,1.68]$ & 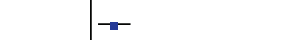 & \\
\hline Liu et al., 2007 & 37 & 43 & 33 & 43 & $9.7 \%$ & $1.12[0.91,1.37]$ & - & \\
\hline Lv, 2009 & 30 & 32 & 23 & 30 & $7.0 \%$ & $1.22[0.98,1.52]$ & $\sigma_{-}$ & \\
\hline Wang ang Jing 2007 & 27 & 31 & 18 & 30 & $5.4 \%$ & $1.45[1.05,2.00]$ & 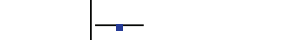 & \\
\hline Wang et al., 2000 & 25 & 34 & 19 & 27 & $6.2 \%$ & $1.04[0.76,1.43]$ & $\leftarrow$ & \\
\hline Wang, 2011 & 19 & 20 & 14 & 20 & $4.1 \%$ & $1.36[1.00,1.84]$ & - & \\
\hline Yang, 2010 & 48 & 50 & 37 & 50 & $10.9 \%$ & $1.30[1.09,1.54]$ & - & \\
\hline Zhang, 2012 & 47 & 50 & 35 & 50 & $10.3 \%$ & $1.34[1.11,1.63]$ & - & \\
\hline Zhao, 2009 & 27 & 30 & 20 & 30 & $5.9 \%$ & $1.35[1.02,1.79]$ & $\mp$ & \\
\hline Total $(95 \% \mathrm{CI})$ & & 522 & & 470 & $100.0 \%$ & $1.29[1.20,1.38]$ & 1 & \\
\hline Total events & 463 & & 327 & & & & & \\
\hline \multicolumn{6}{|c|}{ Heterogeneity: $\mathrm{X}^{2}=5.38, \mathrm{df}=11(P=0.91) ; I^{2}=0 \%$} & 0.01 & 10 & 100 \\
\hline \multicolumn{6}{|c|}{ Test for overall effect: $Z=7.41(P<0.00001)$} & Favours [TAMs or plus & acebo] Favours $\left[\mathrm{XFZY}^{\prime}\right.$ & YT and TAMs] \\
\hline
\end{tabular}

FIGURE 2: Forest plot of trials comparing XFZYT plus TAMs with TAMs, outcome = RAS.

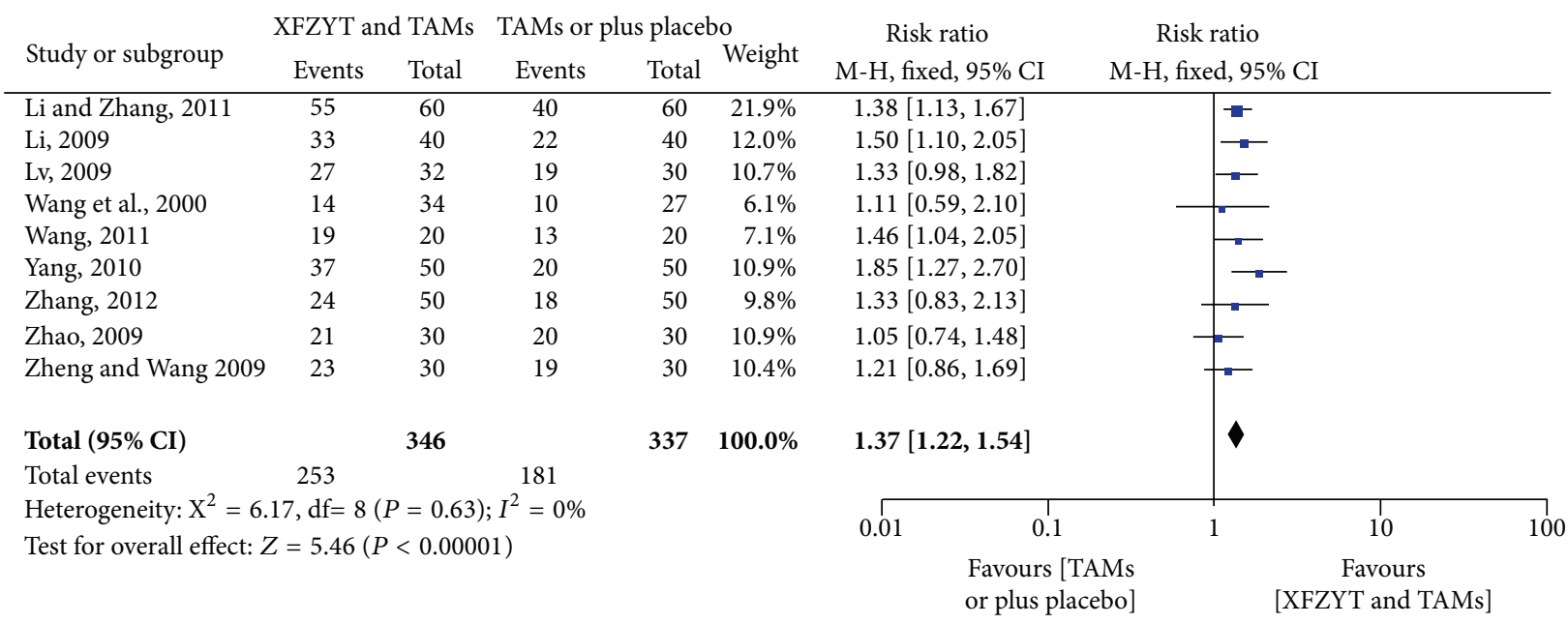

FIgURE 3: Forest plot of trials comparing XFZYT plus TAMs with TAMs, outcome = ECG.

compared with $45.0 \%$ in ECG improvement (therapeutic gain $=32.0 \%$ with an NNT $=3.1$ ) (Table 4 ). (2) For patients with UAP, 76.7\% reported ECG improvement in the experimental group compared with $63.3 \%$ in the control group (therapeutic gain $=13.4 \%$ with an NNT $=7.5$ ) (Table 5). (3) For patients with diagnosis of either SAP or UAP, $86.6 \%$ reported RAS improvement in the experimental group compared with $69.1 \%$ in the control group (therapeutic gain $=17.5 \%$ with an NNT $=5.7$ ) (Table 6), and ECG improvement was 70.8\% versus $52.7 \%$ (therapeutic gain $=18.1 \%$ with an $\mathrm{NNT}=5.5$ ) (Table 7).

3.4. Publication Bias. We performed a funnel plot of the improvement of RAS between XFZYT plus TAMs group and TAMs group (Figure 8). Visual inspection suggested that there was no publication bias.

3.5. Safety. A total of 9 trials $[17,19,20,23-25,28-30]$ mentioned the occurrence of adverse effects. 2 trials [23, 25] of these reported adverse effects in the experiment group (2\%, $3 / 150)$, stomachache, dry mouth, and loose stool included. Other 2 trials $[19,24]$ reported adverse effects in the control group $(3.3 \%, 4 / 121)$, including stomachache, dizziness, and headache. And the remaining 5 trials [17, 20, 28-30] reported that no adverse effects occurred. And no serious adverse effects were reported.

\section{Discussions}

We performed a series of meta-analyses involving 14 RCTs with a total of 1116 participants, and what we can get from this review are as follows: (1) XFZYT combined with TAMs was more effective than TAMs alone for treating patients diagnosed with AP. It could significantly improve ECG and the relief of AP symptoms. The combination therapy of XFZYT and TAMs could also reduce the nitroglycerin use, improve blood HDL-C level which benefits patients with cardiovascular diseases [33], and decrease blood LDL-C, TG, 


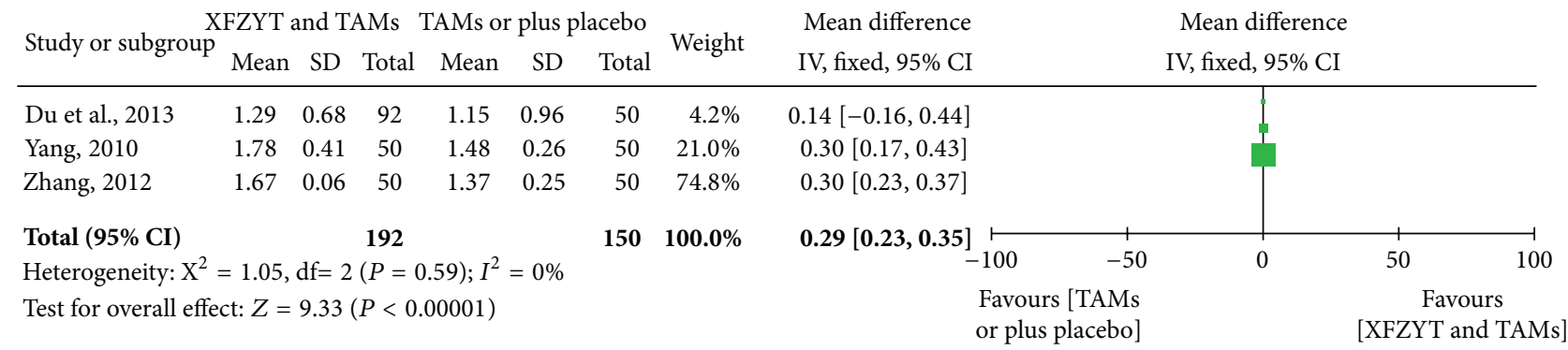

FIGURE 4: Forest plot of trials comparing XFZYT plus TAMs with TAMs, outcome = blood HDL-C level (mmol/L).

\begin{tabular}{lcccccccccc} 
& \multicolumn{1}{c}{ XFZYT and TAMs } & \multicolumn{2}{c}{ TAMs or plus placebo } & \multicolumn{2}{c}{ Mean difference } & \multicolumn{2}{c}{ Mean difference } \\
Study or subgroup, random, 95\% CI
\end{tabular}

FIGURE 5: Forest plot of trials comparing XFZYT plus TAMs with TAMs, outcome = blood LDL-C level (mmol/L).

and TC level which seemed as risk factors of cardiovascular disease [34]. No significant differences were identified on the incidence of adverse effects between XFZYT plus TAMs and TAMs. (2) For patients with UAP, XFZYT combined with TAMs could improve ECG and quality of life in some aspects. The data of RAS was not reported, so we could not make a conclusion about the efficacy of XFZYT plus TAMs in improving RAS on patients with UAP. (3) The therapeutic gain and NNT showed that the SAP group could get more clinical benefits from the add-on effect of XFZYT than other groups. So XFZYT may be a more suitable choice for treating patients with SAP than those with UAP.

We are not able to make confident statements about the safety of XFZYT for reason of insufficient RCTs included and the short treatment duration, nor can we draw firm conclusion that XFZYT can benefit patients with UAP, for there was only one RCT [24] included into the meta-analysis and only the data of ECG improvement was reported; the NNT of the UAP group for ECG improvement (NNT = 7.5) was also larger compared with the other two groups. Although one RCT [23] with superior methodological quality showed that XFZYT can improve the quality of life of patients with UAP after PCI, more studies should be performed to confirm the efficacy of XFZYT for treating patients with UAP.

However, our meta-analysis showed that patients with SAP could get more clinical benefits such as RAS and ECG improvement from the add-on effect of XFZYT compared with the other two groups. We also found that the NNT varied from 3.7 to 32.3 for RAS improvement and from 3.6 to 23.8 for ECG improvement in the SAP and UAP group, which may be relevant to the variance in the percent of SAP of each study. But we failed to detect the correlation coefficient between the therapeutic gain and the percent of SAP, due to the fact that the number of patients with SAP in each included study was not reported. So the future studies should pay attention to the difference of the outcomes between SAP and UAP patients after the treatment with XFZYT, which may have important implication for clinical practice.

There are also limitations to this study. Visual inspection of the funnel plot revealed symmetry, so the publication bias may be minimized. But the methodological quality of the trials included was generally not high; only $3[19,23,25]$ of these RCTs were scored as having superior quality. And only two RCTs $[19,23]$ mentioned allocation concealment process, so the potential selection bias may exist. A few trials mentioned the blinding and withdrawal/dropout, and no multicenter, large sample, and cooperative RCTs were included. Apart from the limitations on the mediocre methodological quality of included studies, for outcome measures of patients with UAP, only the quality of life and ECG improvement were reported, and the estimates of some outcomes, such as the blood lipid level and reduction of nitroglycerin use, were limited by relatively small sample size, which may influence the precision of estimates.

\section{Conclusion}

In summary, these data suggest that XFZYT combined with TAMs is more effective than TAMs alone at improving the clinical symptoms of patients with AP, especially with SAP. And there is no significant difference in the incidence of adverse effects. XFZYT combined with TAM may be an alternative option for patients suffering from AP. However, most 


\begin{tabular}{|c|c|c|c|c|c|c|c|c|c|c|c|c|}
\hline Study or subgroup & \multicolumn{3}{|c|}{ XFZYT and TAMs $\mathrm{T}$} & $\begin{array}{l}\text { Ms TA } \\
\text { Mean }\end{array}$ & \multicolumn{3}{|c|}{ AMs or plus placebo } & Mean difference & \multicolumn{2}{|c|}{ Mean difference } & $\begin{array}{l}\text { erence } \\
95 \% \text { CI }\end{array}$ & \\
\hline Du et al., 2013 & 0.74 & 0.84 & 92 & 0.02 & 0.86 & 50 & $33.2 \%$ & $0.72[0.43,1.01]$ & & 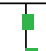 & & \\
\hline Yang, 2010 & 2.13 & 0.73 & 50 & 0.12 & 0.81 & 50 & $33.2 \%$ & $2.01[1.71,2.31]$ & & 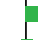 & & \\
\hline Zhang, 2012 & 0.28 & 0.5 & 50 & 0.05 & 0.6 & 50 & $33.6 \%$ & $0.23[0.01,0.45]$ & & 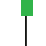 & & \\
\hline Total $(95 \% \mathrm{CI})$ & & & 192 & & & 150 & $100.0 \%$ & $0.98[-0.05,2.02]$ & & & & \\
\hline Heterogeneity: $\tau^{2}=$ & $=0.81 ;$ & $\mathrm{X}^{2}=88$ & $8.48, \mathrm{~d}$ & $f=2(P$ & 0.0000 & 1); $I^{2}$ & $=98 \%$ & -100 & -50 & 0 & 50 & 100 \\
\hline Test for overall effec & ct: $Z=$ & 1.87 & $(P=0$ & $.06)$ & & & & & $\begin{array}{l}\text { [TAM } \\
\text { lacebo }\end{array}$ & & Fav & [AMs] \\
\hline
\end{tabular}

FIGURE 6: Forest plot of trials comparing XFZYT plus TAMs with TAMs, outcome = blood TG level (mmol/L).

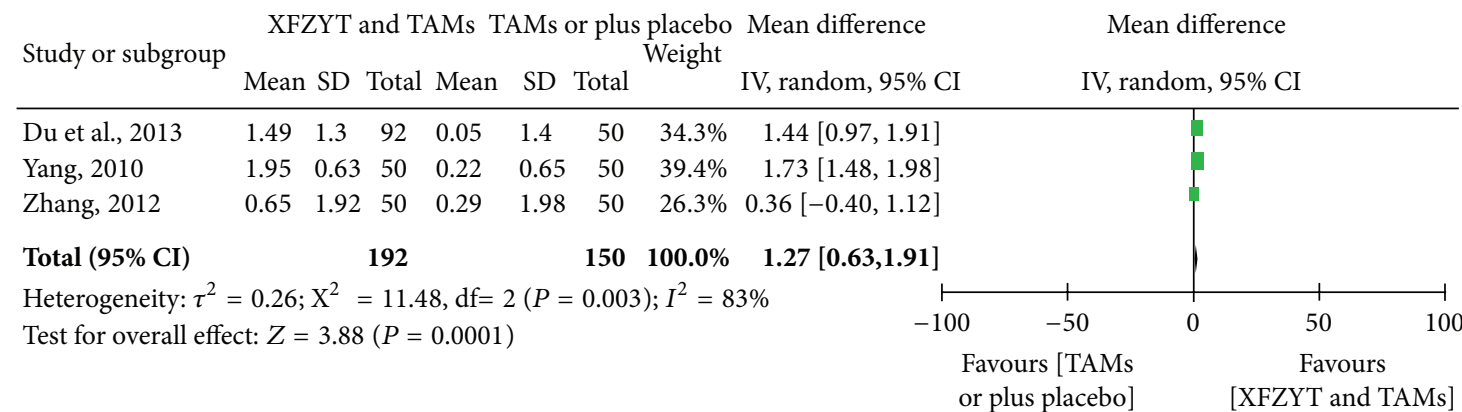

FIgURE 7: Forest plot of trials comparing XFZYT plus TAMs with TAMs, outcome = blood TC level (mmol/L).

TABLE 3: The effect of XFZYT for SAP group, outcome = RAS.

\begin{tabular}{|c|c|c|c|c|c|c|}
\hline \multirow{2}{*}{ Study ID } & \multirow{2}{*}{$\begin{array}{c}\text { Treatment } \\
\text { duration }\end{array}$} & \multicolumn{2}{|c|}{ Response rate, \%; (response $/ N$ ) } & \multirow{2}{*}{$\begin{array}{l}\text { Therapeutic } \\
\text { gain, } \%\end{array}$} & \multirow{2}{*}{ NNT } & \multirow{2}{*}{$\mathrm{RR}$} \\
\hline & & Experimental & Control & & & \\
\hline $\mathrm{Li}, 2008[21]$ & 4 weeks & $95.0(38 / 40)$ & $70.0(28 / 40)$ & 25.0 & 4.0 & 1.36 \\
\hline Wang, $2011[28]$ & 8 weeks & $95.0(19 / 20)$ & $70.0(14 / 20)$ & 25.0 & 4.0 & 1.36 \\
\hline Zhao, 2009 [26] & 4 weeks & $90.0(27 / 30)$ & $66.7(20 / 30)$ & 23.3 & 4.3 & 1.35 \\
\hline Yang, $2010[18]$ & 4 weeks & $96.0(48 / 50)$ & $74.0(37 / 50)$ & 22.0 & 4.5 & 1.30 \\
\hline Pooled RR & - & $94.3(132 / 140)$ & $70.7(99 / 140)$ & 23.6 & 4.2 & 1.33 \\
\hline
\end{tabular}

NNT: number needed to treat; RR: risk ratio.

TABLE 4: The effect of XFZYT for SAP group, outcome = ECG.

\begin{tabular}{|c|c|c|c|c|c|c|}
\hline \multirow{2}{*}{ Study ID } & \multirow{2}{*}{$\begin{array}{c}\text { Treatment } \\
\text { duration }\end{array}$} & \multicolumn{2}{|c|}{ Response rate, \%; (response/N) } & \multirow{2}{*}{$\begin{array}{l}\text { Therapeutic } \\
\text { gain, } \%\end{array}$} & \multirow{2}{*}{$\mathrm{NNT}$} & \multirow{2}{*}{$\mathrm{RR}$} \\
\hline & & Experimental & Control & & & \\
\hline $\mathrm{Li}, 2008[21]$ & 4 weeks & NA & NA & - & - & - \\
\hline Wang, 2011 [28] & 8 weeks & $95.0(19 / 20)$ & $65.0(13 / 20)$ & 30.0 & 3.3 & 1.46 \\
\hline Zhao, 2009 [26] & 4 weeks & $70.0(21 / 30)$ & $40.0(12 / 30)$ & 30.0 & 3.3 & 1.75 \\
\hline Yang, 2010 [18] & 4 weeks & $74.0(37 / 50)$ & $40.0(20 / 50)$ & 34.0 & 2.9 & 1.85 \\
\hline Pooled RR & - & $77.0(77 / 100)$ & $45.0(45 / 100)$ & 32.0 & 3.1 & 1.71 \\
\hline
\end{tabular}

NNT: number needed to treat; NA: not available; RR: risk ratio.

TABLE 5: The effect of XFZYT for UAP group, outcome = ECG.

\begin{tabular}{|c|c|c|c|c|c|c|}
\hline \multirow{2}{*}{ Study ID } & \multirow{2}{*}{$\begin{array}{l}\text { Treatment } \\
\text { duration }\end{array}$} & \multicolumn{2}{|c|}{ Response rate, \%; (response/N) } & \multirow{2}{*}{$\begin{array}{l}\text { Therapeutic } \\
\text { gain, } \%\end{array}$} & \multirow{2}{*}{ NNT } & \multirow{2}{*}{$\mathrm{RR}$} \\
\hline & & Experimental & Control & & & \\
\hline $\begin{array}{l}\text { Zheng and Wang, } \\
2009 \text { [24] }\end{array}$ & 8 weeks & $76.7(23 / 30)$ & $63.3(19 / 30)$ & 13.4 & 7.5 & 1.21 \\
\hline Pooled RR & - & $76.7(23 / 30)$ & $63.3(19 / 30)$ & 13.4 & 7.5 & 1.21 \\
\hline
\end{tabular}

NNT: number needed to treat; RR: risk ratio. 
TABLE 6: The effect of XFZYT for SAP and UAP group, outcome = RAS.

\begin{tabular}{|c|c|c|c|c|c|c|}
\hline \multirow{2}{*}{ Study ID } & \multirow{2}{*}{$\begin{array}{l}\text { Treatment } \\
\text { duration }\end{array}$} & \multicolumn{2}{|c|}{ Response rate, \%; (response/N) } & \multirow{2}{*}{$\begin{array}{c}\text { Therapeutic } \\
\text { gain, } \%\end{array}$} & \multirow{2}{*}{ NNT } & \multirow{2}{*}{$\mathrm{RR}$} \\
\hline & & Experimental & Control & & & \\
\hline Lv, 2009 [22] & 4 weeks & $93.8(30 / 32)$ & $76.7(23 / 30)$ & 17.1 & 5.8 & 1.22 \\
\hline Wang et al., 2000 [18] & 4 weeks & $73.5(25 / 34)$ & $70.4(19 / 27)$ & 3.1 & 32.3 & 1.04 \\
\hline Du et al., 2013 [29] & 6 weeks & $79.3(73 / 92)$ & $64.0(32 / 50)$ & 15.3 & 6.5 & 1.24 \\
\hline $\begin{array}{l}\text { Wang and Jing, } 2007 \\
\text { [19] }\end{array}$ & 4 weeks & $87.1(27 / 31)$ & $60.0(18 / 30)$ & 27.1 & 3.7 & 1.45 \\
\hline $\begin{array}{l}\text { Li and Zhang, } 2011 \\
\text { [27] }\end{array}$ & 4 weeks & $90.0(54 / 60)$ & $66.7(40 / 60)$ & 23.3 & 4.3 & 1.35 \\
\hline Liu et al., 2007 [25] & 8 weeks & $86.0(37 / 43)$ & $76.7(33 / 43)$ & 9.4 & 10.6 & 1.12 \\
\hline Zhang, 2012 [17] & 4 weeks & $94.0(47 / 50)$ & $70.0(35 / 50)$ & 24.0 & 4.2 & 1.34 \\
\hline $\mathrm{Li}, 2009[30]$ & 4 weeks & $95.0(38 / 40)$ & $70.0(28 / 40)$ & 25.0 & 4.0 & 1.36 \\
\hline Pooled RR & - & $86.6(331 / 382)$ & $69.1(228 / 330)$ & 17.5 & 5.7 & 1.25 \\
\hline
\end{tabular}

NNT: number needed to treat; RR: risk ratio.

TABLE 7: The effect of XFZYT for SAP and UAP group, outcome = ECG.

\begin{tabular}{|c|c|c|c|c|c|c|}
\hline \multirow{2}{*}{ Study ID } & \multirow{2}{*}{$\begin{array}{c}\text { Treatment } \\
\text { duration }\end{array}$} & \multicolumn{2}{|c|}{ Response rate, \%; (response/N) } & \multirow{2}{*}{$\begin{array}{l}\text { Therapeutic } \\
\text { gain, } \%\end{array}$} & \multirow{2}{*}{ NNT } & \multirow{2}{*}{$\mathrm{RR}$} \\
\hline & & Experimental & Control & & & \\
\hline Lv, 2009 [22] & 4 weeks & $84.4(27 / 32)$ & $63.3(19 / 30)$ & 21.1 & 4.7 & 1.33 \\
\hline Wang et al., 2000 [18] & 4 weeks & $41.2(14 / 34)$ & $37.0(10 / 27)$ & 4.2 & 23.8 & 1.11 \\
\hline Du et al., 2013 [29] & 6 weeks & NA & NA & - & - & - \\
\hline $\begin{array}{l}\text { Wang and Jing, } 2007 \\
{[19]}\end{array}$ & 4 weeks & NA & NA & - & - & - \\
\hline $\begin{array}{l}\text { Li and Zhang, } 2011 \\
\text { [27] }\end{array}$ & 4 weeks & $91.7(55 / 60)$ & $66.7(40 / 60)$ & 25.0 & 4.0 & 1.37 \\
\hline Liu et al., 2007 [25] & 8 weeks & NA & NA & - & - & - \\
\hline Zhang, 2012 [17] & 4 weeks & $48.0(24 / 50)$ & $36.0(18 / 50)$ & 12.0 & 8.3 & 1.33 \\
\hline $\mathrm{Li}, 2009[30]$ & 4 weeks & $82.5(33 / 40)$ & $55.0(22 / 40)$ & 27.5 & 3.6 & 1.50 \\
\hline Pooled RR & - & $70.8(153 / 216)$ & $52.7(109 / 207)$ & 18.1 & 5.5 & 1.34 \\
\hline
\end{tabular}

NNT: number needed to treat; NA: not available; RR: risk ratio.

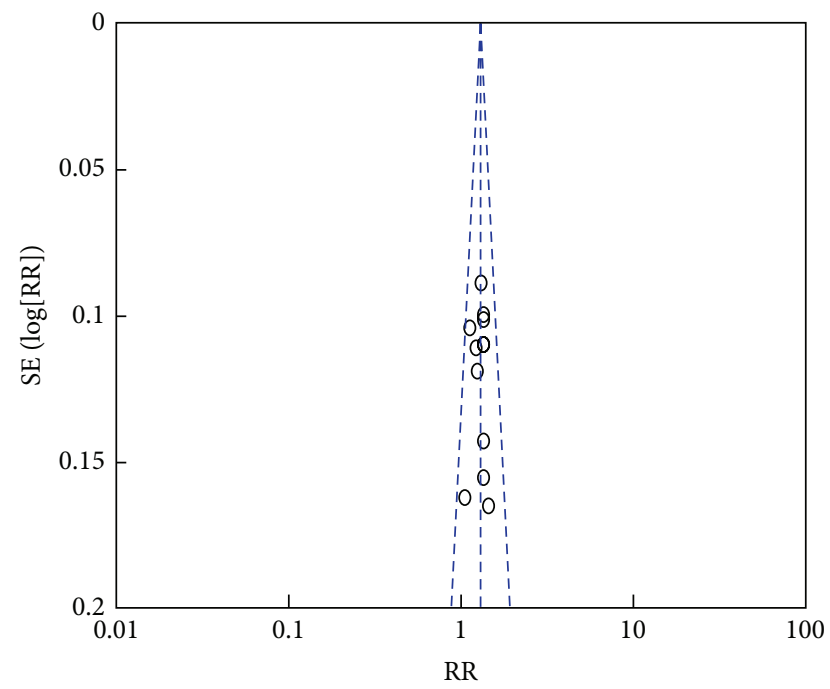

Figure 8: Funnel plot of trials comparing XFZYT plus TAMs with TAMs, outcome $=$ RAS. of included RCTs were scored as having mediocre methodological quality; the findings should be interpreted with caution. Hence, future studies of XFZYT in the treatment of $\mathrm{AP}$ are warranted in rigorously designed, multicentre, and large-scale trials worldwide.

\section{Conflict of Interests}

All the authors declare that there is no conflict of interests.

\section{Authors' Contribution}

L. X. Yuan contributed to the design of the study and analytic strategy; G. Z. Yi, Y. Q. Qiu, and Y. Xiao searched the literature and extracted the data; G. Z. Yi analyzed the data and wrote the paper.

\section{Acknowledgment}

All the authors are indebted to the authors of the primary studies. 


\section{References}

[1] Global Status Report on Noncommunicable Diseases 2010, World Health Organization, Geneva, Switzerland, 2011, http://www .who.int/nmh/publications/ncd_report2010/en/.

[2] World Health Organization, Global Atlas on Cardiovascular Disease Prevention and Control, WHO, Geneva, Switzerland, 2011.

[3] H. H. Gray, R. A. Henderson, M. A. de Belder, S. R. Underwood, and A. J. Camm, "Early management of unstable angina and non-ST-segment elevation myocardial infarction: summary of NICE guidance," Heart, vol. 96, no. 20, pp. 1662-1668, 2010.

[4] R. A. Henderson and N. O’Flynn, "Management of stable angina: summary of NICE guidance," Heart, vol. 98, no. 6, pp. 500-507, 2012.

[5] R. Parikh and P. J. Kadowitz, "Angina pectoris: current therapy and future treatment options," Expert Review of Cardiovascular Therapy, vol. 12, no. 2, pp. 175-186, 2014.

[6] W. Hueb, P. R. Soares, B. J. Gersh et al., "The medicine, angioplasty, or surgery study (MASS-II): a randomized, controlled clinical trial of three therapeutic strategies for multivessel coronary artery disease: one-year results," Journal of the American College of Cardiology, vol. 43, no. 10, pp. 1743-1751, 2004.

[7] H. F. Wang, H. Shi, and Y. Xia, "Research progress of Xuefu Zhuyu decoction in the treatment of Cardiovascular and Cerebrovascular Disease," China Journal of Chinese Medicine, vol. 28, no. 11, pp. 1732-1734, 2013.

[8] D. Su and L. Yao, "Modern pharmacological research of xuefu zhuyu decoction," Acta Chinese Medicine and Pharmacology, vol. 41, no. 3, pp. 172-175, 2013.

[9] W. L. Shi, J. S. Zhang, Y. Q. Hu et al., "The research of clinical application and mechanism of Xuefu Zhuyu Tang in preventing and treating vascular disease," Chinese Journal of Integrated Traditional and Western Medicine, vol. 33, no. 5, pp. 712-716, 2013.

[10] X. Wu, "Progress of clinical and experimental study on the application of Xuefu Zhuyu Tang," CJGMCM, vol. 28, no. 3, pp. 635-637, 2013.

[11] E. Braunwald, E. M. Antman, J. W. Beasley et al., "ACC/AHA guidelines for the management of patients with unstable angina and non-ST-segment elevation myocardial infarction: executive summary and recommendations: a report of the American College of Cardiology/American Heart Association task force on practice guidelines (committee on the management of patients with unstable angina)," Circulation, vol. 102, no. 10, pp. 1193-1209, 2000.

[12] "Nomenclature and criteria for diagnosis of ischemic heart disease. Report of the Joint International Society and Federation of Cardiology/World Health Organization task force on standardization of clinical nomenclature," Circulation, vol. 59, no. 3, pp. 607-609, 1979.

[13] "Recommendations for the diagnosis and treatment of unstable angina pectoris," Chinese Journal of Cardiology, vol. 28, no. 6, pp. 8-11, 2000.

[14] "Guideline for the diagnosis and treatment of stable angina pectoris," Chinese Journal of Cardiology, vol. 28, no. 3, pp. 195206, 2007.

[15] "The curative effect standard for angina pectoris symptoms and ECG (Symposium of integrated traditional Chinese and Western medicine for treatment of angina pectoris of coronary heart disease and arrhythmia, 1979, Shanghai)," Chinese Pharmaceutical Affairs, vol. 1, no. 2, pp. 17-20, 1987.
[16] J. Higgins and S. Green, Cochrane Handbook for Systematic Reviews of Interventions, Version 5.1.0, The Cochrane Collaboration, 2011, http://handbook.cochrane.org/.

[17] S. J. Zhang, "Comparative study of the efficacy of different formulations of traditional Chinese medicine in the treatment of blood stasis type of unstable angina," China Modern Medicine, vol. 19, no. 18, pp. 11-13, 2012.

[18] Y. J. Yang, "Shenqi Zhuyu Decoction: clinical observation of 50 cases with western medicine in the treatment angina pectoris of coronary heart disease," Journal of Sichuan of Traditional Chinese Medicine, vol. 28, no. 7, pp. 63-65, 2010.

[19] J. Wang and L. Jing, "Clinical research of compound Chinese medicine based on combination of disease and syndrome," World Science and Technology Modernization of Traditional Chinese Medicine and Materia Medica, vol. 9, no. 1, pp. 16-20, 2007.

[20] W. Wang, X. C. Ma, X. F. Wang et al., "Clinical observation on 30 cases of refined Xuefu Zhuyu Capsule in treatment of angina pectoris of coronary heart disease," Journal of Traditional and Complementary Medicine, vol. 41, no. 8, pp. 471-473, 2000.

[21] D. B. Li, "Clinical observation of combined with Xuefu Zhuyu Capsule in treatment of angina pectoris of coronary heart disease in 40 cases," Beijing Journal of Traditional Chinese Medicine, vol. 27, no. 10, pp. 810-811, 2008.

[22] G. Lv, "Combined with Zhuyu Decoction in treating stasis angina pectoris of coronary heart disease 32 cases," Guangxi Journal of Traditional Chinese Medicine, vol. 32, no. 6, pp. 3536, 2009.

[23] F.-Y. Chu, J. Wang, X.-W. Sun et al., "A randomized doubleblinded controlled trial of Xuefu Zhuyu Capsule on short-term quality of life in unstable anginal patients with blood-stasis syndrome after percutaneous coronary intervention," Journal of Chinese Integrative Medicine, vol. 7, no. 8, pp. 729-735, 2009.

[24] G.-L. Zheng and S.-H. Wang, "Clinical effect and mechanismn of xuefu zhuyu capsule in treating unstable angina pectoris," CJITWM, vol. 29, no. 1, pp. 65-68, 2009.

[25] J. G. Liu, H. Xu, G. J. Dong et al., "Effect of Xuefu Zhuyu oral liquid on expression of activation molecules of platelet in patients with coronary heart disease and angina pectoris," Journal of Changchun University of Traditional Chinese Medicine, vol. 23, no. 1, pp. 29-31, 2007.

[26] S. L. Zhao, "60 cases observation of Xuefu Zhuyu Tang on clinical curative effect and coagulation index of patients with angina pectoris," in Proceedings of the 3rd Academic Conference on Thrombotic Disease of Traditional Chinese Medicine Association, Thrombus Disease Branch of Chinese Medicine Association, 2009.

[27] J. L. Li and Q. M. Zhang, "The curative effect Xuefu Zhuyu Decoction in treating coronary heart disease and angina pectoris: observation of 60 cases," Chinese Journal of Integrative Medicine on Cardio-/Cerebrovascular Disease, vol. 9, no. 12, pp. 1412-1413, 2011.

[28] C. X. Wang, The clinic study on curative effect of the Xuefu Zhuyu Decoction with isosorbide mononitrate in treating angina pectoris [Dissertation, thesis], Nanjing University of Chinese Medicine, 2011.

[29] Z. L. Du, D. L. Chen, and J. L. Chen, "Random Parallel Study of Xuefu Zhuyu Tang combined with Western Medicine in the treatment of coronary heart disease and angina pectoris," Journal of Practical Traditional Chinese Internal Medicine, vol. 27, no. 2, pp. 85-87, 2013. 
[30] G. C. Li, "Observation of the curative effect of Xuefu Zhuyu Tang on treating coronary heart disease and angina pectoris," Henan Traditional Chinese Medicine, vol. 29, no. 12, pp. 12261227, 2009.

[31] J. A. Spertus, J. A. Winder, T. A. Dewhurst et al., "Development and evaluation of the Seattle Angina Questionnaire: a new functional status measure for coronary artery disease," Journal of the American College of Cardiology, vol. 25, no. 2, pp. 333-341, 1995.

[32] C. Jenkinson, L. Wright, and A. Coulter, "Criterion validity and reliability of the SF-36 in a population sample," Quality of Life Research, vol. 3, no. 1, pp. 7-12, 1994.

[33] G. Rajagopal, V. Suresh, and A. Sachan, "High-density lipoprotein cholesterol: how High," Indian Journal of Endocrinology and Metabolism, vol. 16, no. 2, pp. 236-238, 2012.

[34] J. Nuotio, M. Oikonen, C. G. Magnussen et al., "Cardiovascular risk factors in 2011 and secular trends since 2007: The Cardiovascular Risk in Young Finns Study," Scandinavian Journal of Public Health, 2014. 


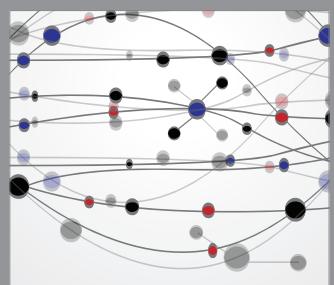

The Scientific World Journal
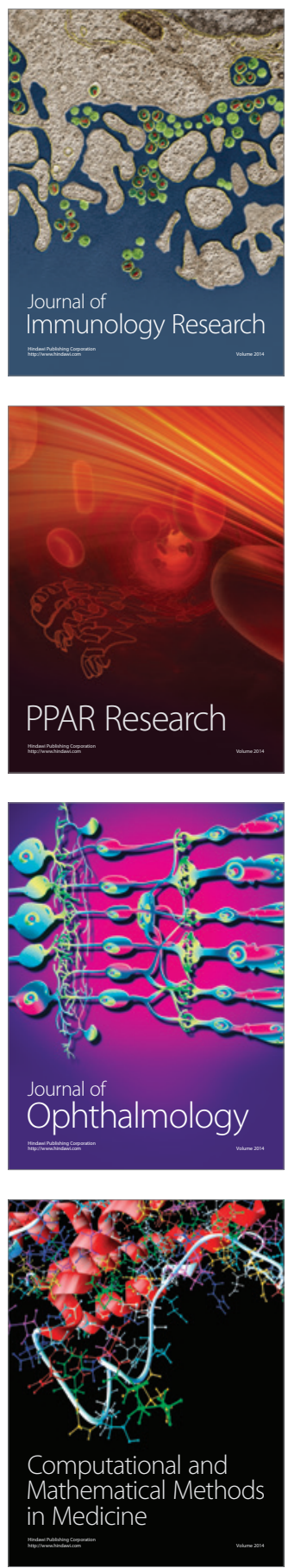

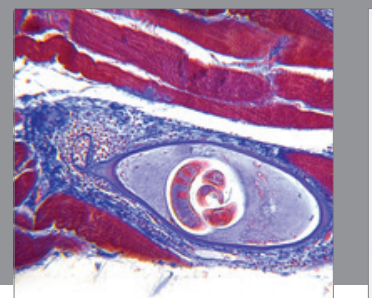

Gastroenterology

Research and Practice
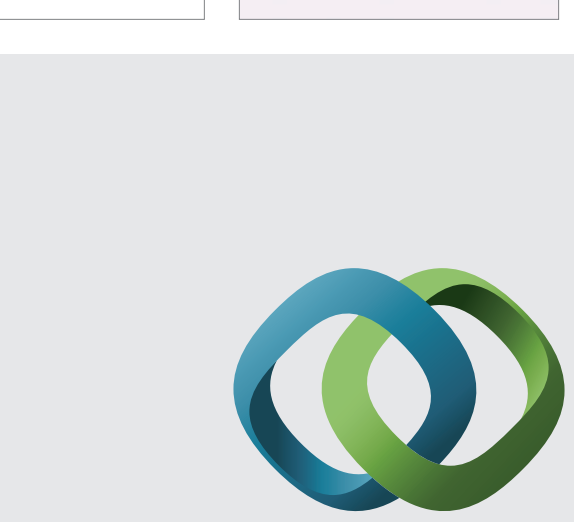

\section{Hindawi}

Submit your manuscripts at

http://www.hindawi.com
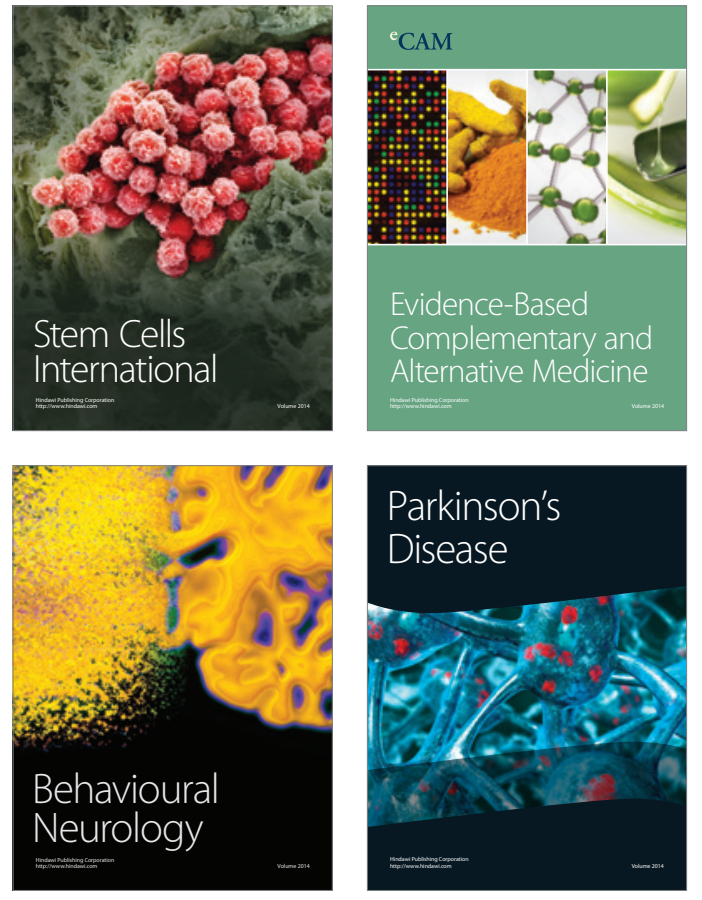
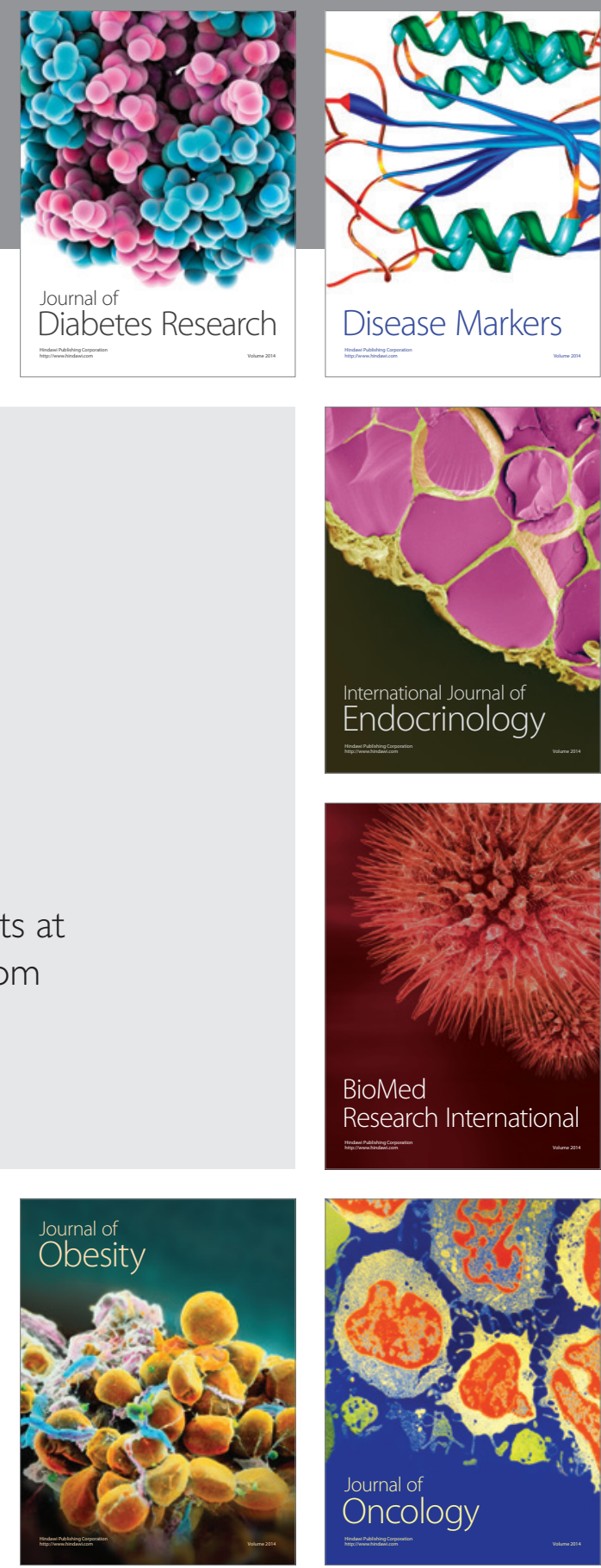

Disease Markers
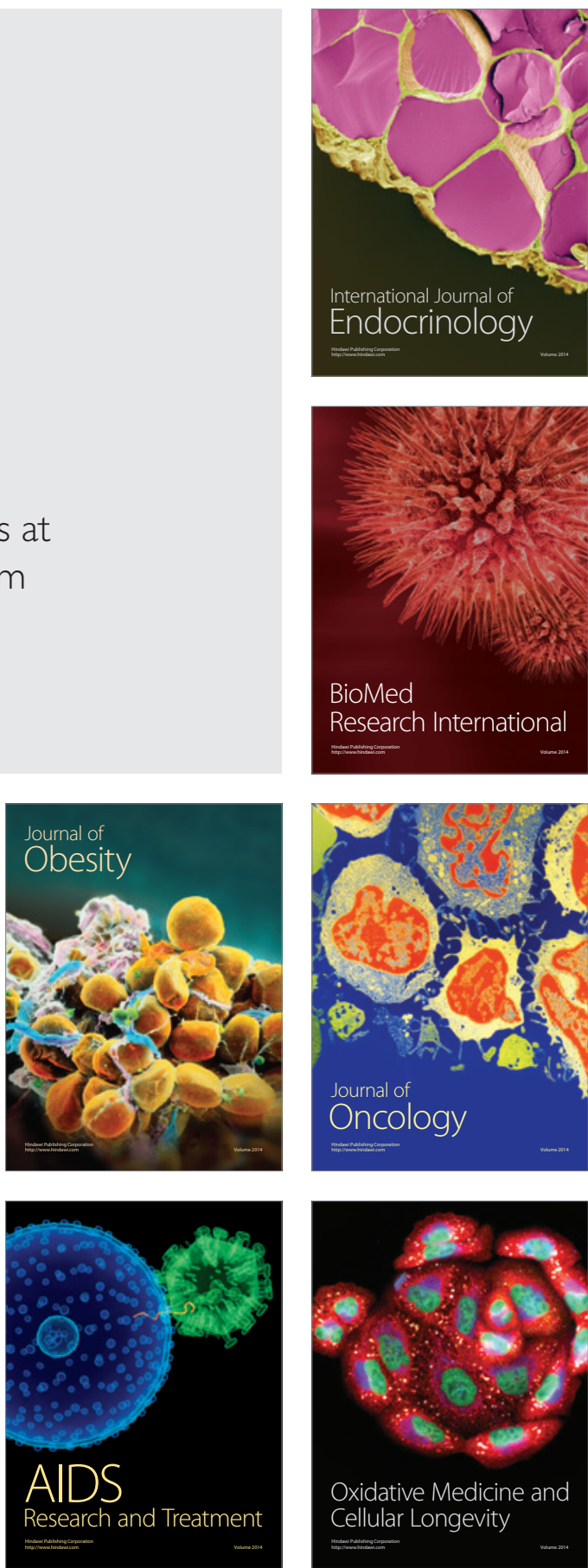